\title{
The role of imaging in acute pancreatitis
}

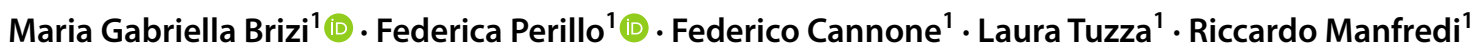

Received: 14 October 2020 / Accepted: 19 April 2021 / Published online: 12 May 2021

(c) The Author(s) 2021

\begin{abstract}
Acute pancreatitis is one of the most commonly encountered etiologies in the emergency setting, with a broad spectrum of findings that varies in severity from mild interstitial pancreas to severe forms with significant local and systemic complications that are associated with a substantial degree of morbidity and mortality. In this article the radiological aspect of the terminology and classification of acute pancreatitis are reviewed. The roles of ultrasound, computed tomography, and magnetic resonance imaging in the diagnosis and evaluation of acute pancreatitis and its complications are discussed. The authors present a practical image-rich guide, applying the revised Atlanta classification system, with the goal of facilitating radiologists to write a correct report, and reinforcing the radiologist's role as a key member of a multidisciplinary team in treating patients with acute pancreatitis. Computed tomography is the most performed imaging test for acute pancreatitis. Nevertheless, MRI is useful in many specific situations, due to its superiority soft tissue contrast resolution and better assessment of biliary and pancreatic duct, for example in the ductal disconnection. The purpose if this article is to review recent advances in imaging acquisition and analytic techniques in the evaluation of AP.
\end{abstract}

Keywords Acute pancreatitis · Computed tomography $(\mathrm{CT}) \cdot \mathrm{MRI} \cdot$ Magnetic resonance cholangiopancreatography $(\mathrm{MRCP}) \cdot$ Interstitial edematous pancreatitis $\cdot$ Necrotizing Pancreatitis

\section{Definition}

Acute pancreatitis (AP), an inflammatory disorder of the pancreas, refers to the autodigestion of the pancreas, in which pancreatic enzymes injure pancreatic tissue and lead to dysfunction of the gland, as well as remote organs and systems. The epidemiology of diseases often changes with time-for pancreatitis, this aspect is certainly true. The

Federica Perillo

federicaperi30@gmail.com

Maria Gabriella Brizi

mariagabriella.brizi@unicatt.it

Federico Cannone

federicocannone@hotmail.com

Laura Tuzza

laura.tuzza@gmail.com

Riccardo Manfredi

riccardo.manfredi@unicatt.it

1 Dipartimento di diagnostica per immagini, Radioterapia, Oncologia ed Ematologia, Fondazione Universitaria “A. Gemelli", IRCCS - Università Cattolica del Sacro Cuore, Largo Agostino Gemelli, 8, 00168 Rome, Italy reasons for such changes are many: population growth and migration, change in patterns of alcohol consumption and tobacco smoking, rising rates of obesity and recognition of metabolic causes of pancreatitis, and increasing use and improving quality of imaging modalities [1-3].

\section{Epidemiology}

\section{Incidence}

The global pooled incidence of AP is 34 cases per 100,000 general population per year [95\% confidence interval (CI) 23-49], with no statistically significant difference between men and women [4]. The disease predominantly affects people between 60 and 75 years old [5]. Also, we can identify regions with high incidence (that are, those with incidence more than 34 cases per 100,000 general population per year) are the North America and Western Pacific regions (as defined by the WHO).

Recurrent AP developed in 21\% (95\% Cl 17-26\%) of patients after the first episode of AP, and chronic pancreatitis 
developed in 36\% (95\% $\mathrm{Cl} 20-53 \%$ ) of patients after recurrent acute pancreatitis [1].

\section{Prevalence}

The notion of prevalence is typically considered in the context of chronic diseases, yet the prevalence of acute conditions can also be of importance [1]. The pancreatologists had not focused their attention on estimating the prevalence of $\mathrm{AP}$, because it was believed that the majority of patients do not develop long-term consequences, while data suggest that even patients with mild AP (around 80\%) have at least twofold higher long-term risk of diabetes mellitus than people in the general population $[6,7]$. Thus, a knowledge of prevalence might enable quantification of the predicted burden of sequelae attributable to acute pancreatitis in the general population and guide the effective allocation of health care resources [1].

\section{Mortality}

The pooled mortality from an episode of AP in seven population-based cohort studies evaluated in the systematic review by Xiao et al. [4] was 1.16 (95\% CI 0.85-1.58) per 100,000 general population per year. Determinants for increased risk for mortality in AP are well-established and include persistent organ failure and infected pancreatic necrosis [8-10]. There are two peaks of lethality in AP: the first one, connected with early dysfunction of organs, begins after one week from the disease onset; the second peak, connected with infected centre's of necrosis, onsets from the second week of the disease.

\section{Clinical presentation}

AP is an inflammatory condition of the pancreas that can cause local injury, systemic inflammatory response syndrome, and organ failure; worldwide AP is a common condition associated with substantial suffering, morbidity, and cost to the health care system [11]. According to the revised Atlanta classification, accurate diagnosis of AP requires at least two of the following three diagnostic features [12]:

(1) Abdominal pain consistent with AP.

(2) Serum lipase or amylase levels that are at least 3 times the upper limit of the normal range, and

(3) Findings of AP on cross-sectional imaging (computed tomography $-\mathrm{CT}$ - or magnetic resonance imaging MRI).
If abdominal pain suggests strongly that $\mathrm{AP}$ is present, but the serum amylase and/or lipase activity is less than three times the upper limit of normal, as may be the case with delayed presentation, imaging will be required to confirm the diagnosis [13, 14]. If the diagnosis of AP is established by abdominal pain and by increases in the serum pancreatic enzyme activities, a CT is not usually required for diagnosis in the emergency room or on admission to the hospital. The onset of the pancreatitis is considered to coincide with the 1 st day of pain, not the day on which the patient presents for care or the day of hospital admission [15].

\section{Phases of AP}

AP is divided into early and late phases.

- The early phase-first week after the onset-is characterized by activation of the cytokine cascade with resultant systemic inflammatory response syndrome (SIRS). If SIRS persists there is an increased risk of developing organ failure, that can be- transient-if it resolves within $48 \mathrm{~h}$ or-persistent—if it persists for $>48 \mathrm{~h} \mathrm{[16-18].}$

- The late phase, starting in the 2nd week and can lasts for weeks to months, occurs only in patients with moderately severe or severe pancreatitis, as defined by persistent organ failure and by local complications [12] and it is characterized by the presence of local complications, systemic manifestations and/or by transient or persistent organ failure.

\section{Grading of AP}

According to the revised Atlanta classification, the severity of AP identifies three classes:

- Mild AP, with no organ failure, and no local or systemic complications. Patients with mild AP generally do not require pancreatic imaging, and mortality is very rare [19].

- Moderately severe AP characterized by the presence of transient organ failure or local or systemic complications in the absence of persistent organ failure.

- Severe AP, characterized by persistent organ failure, that may be single or multiple organ failure; these patients can have one or more local complications, and have an increased risk of death [16-18].

To correlate complications and mortality several clinical scoring systems like Marshal or APACHE (Acute Physiology and Chronic Health Disease Classification System) were 
Table 1 Modified CT severity index ${ }^{20}$

\begin{tabular}{lc}
\hline Prognostic indicators & Points \\
\hline Pancreatic inflammation & \\
Normal pancreas & 0 \\
Intrinsic pancreatic abnormalities with ot without inflammatory changes in pancreatic fat & 2 \\
Pancreatic or peripancreatic fluid collection or peripancreatic fat necrosis & 4 \\
Pancreatic necrosis & \\
None & 0 \\
$\leq 30 \%$ & 2 \\
$\geq 30 \&$ & 4 \\
Extrapancreatic complications & \\
One or more of pleural effusion, ascites, vascular complications, parenchymal complications, or & 2 \\
gastrointestinal tract involvement & \\
\hline
\end{tabular}

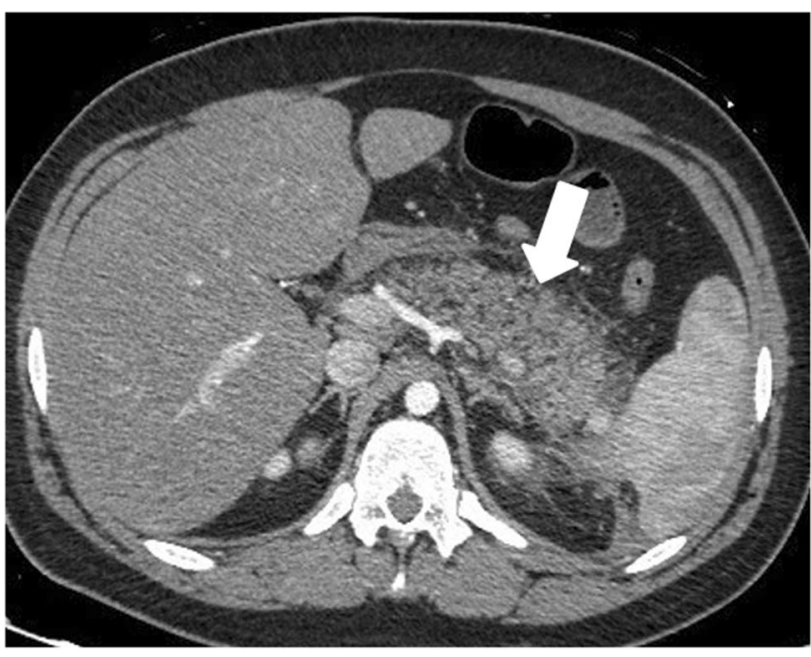

Fig. 1 Interstistial acute pancreatitis in 17-year-old man, after cannabinoids abuse: axial IV contrast-enhanced CT scan shows mild diffuse enlargement of the whole pancreatic gland with poorly defined contours (arrow); the enhancement of the pancreatic parenchyma is normal and there are no foci of glandular necrosis

designed [12]. Balthazar et al. in 1990 introduced instead the CT severity index for assessment of AP. In 2004 Mortele et al. [20] introduced the MCTSI, which includes as prognostic indicators the pancreatic inflammation, the pancreatic necrosis and extrapancreatic complications (Table 1).

\section{IEP versus necrotizing pancreatitis}

AP can be subdivided into two types, according to the pathologic changes: interstitial edematous pancreatitis (IEP) and necrotizing pancreatitis [12].

IEP is more common and represents non necrotizing inflammation of the pancreas. Most patients, above 69\%, have diffuse enlargement of the pancreas, occasionally it is localized, due to inflammatory edema. On contrast-enhanced
Computed Tomography (CECT), the pancreatic parenchyma shows relatively homogeneous enhancement, but there are not unenhanced (necrotic) areas (Fig. 1). The peripancreatic fat usually shows some inflammatory changes of haziness or mild stranding; there may also be some peripancreatic fluid [12] (Fig. 2a); the clinical symptoms usually resolve within the 1 st week.

Five-10\% - of patients with acute pancreatitis develop a necrotizing pancreatitis. The necrosis may involve either the pancreatic parenchyma and/or the peripancreatic tissues. There are three subtypes of necrotizing pancreatitis, based on the anatomic area of necrotic involvement:

- Pancreatic only

- Peripancreatic only

- Combined pancreatic and peripancreatic [15].

Necrotizing pancreatitis most commonly manifests as necrosis involving both the pancreas and peripancreatic tissues in the $75 \%$ of the cases, while less commonly-in the $20 \%$-it manifests as necrosis of only the peripancreatic tissue, and in 5\% as necrosis of the pancreatic parenchyma alone [12]. The combined subtype demonstrates nonenhancing pancreatic parenchyma, as well as non-enhancing heterogeneous peripancreatic collections, and typically accumulating in the lesser sac and anterior pararenal space (Fig. 3). Peripancreatic necrosis alone occurs in $20 \%$ of cases, with normal enhancement of the pancreas, while in the peripancreatic tissues there is necrosis, with collections. Pancreatic necrosis alone (Fig. 2b) is the least common subtype, occurring in $5 \%$ of cases [15].

An early CECT may underestimate the extent of pancreatic and peripancreatic necrosis because the impairment of pancreatic perfusion and signs of peripancreatic necrosis evolve over 7 days, therefore a CT examination should not be performed before $72 \mathrm{~h}$, from the onset of symptoms, in order to grade the severity of the disease $[12,19,21]$. 


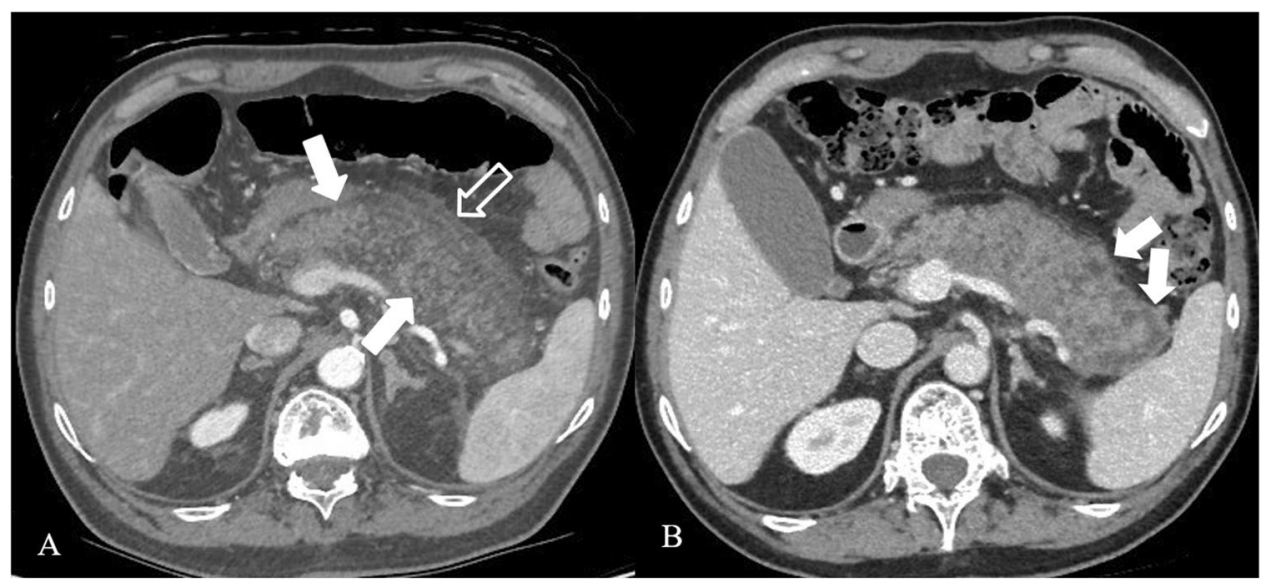

Fig. 2 Acute pancreatitis in a 61 years-old man. The axial contrastenhanced CT scan after 3 days from the onset (a), in pancreatic arterial phase, shows edematous pancreas (arrows), with disomogeneous and reduced enhancement, with no necrotic area in the contest. It is also evident mild peripancreatic fatty stranding (empty arrow). TC study after nine days of the onset (b) shows heterogeneous contrast enhancement of the pancreatic parenchyma, with focal hypovascular areas due to the necrosis (arrows)
Fig. 3 Necrotizing Pancreatitis in a 39 years-old man, with acute abdominal pain and sepsis. Axial contrast-enhanced CT scans during the arterial phase (a) and portal phase (b) show enlarged pancreas with poorly defined contours and decreased enhancement of the pancreatic parenchyma (arrows), surrounded by heterogeneous fluid collection (empty arrows in b)

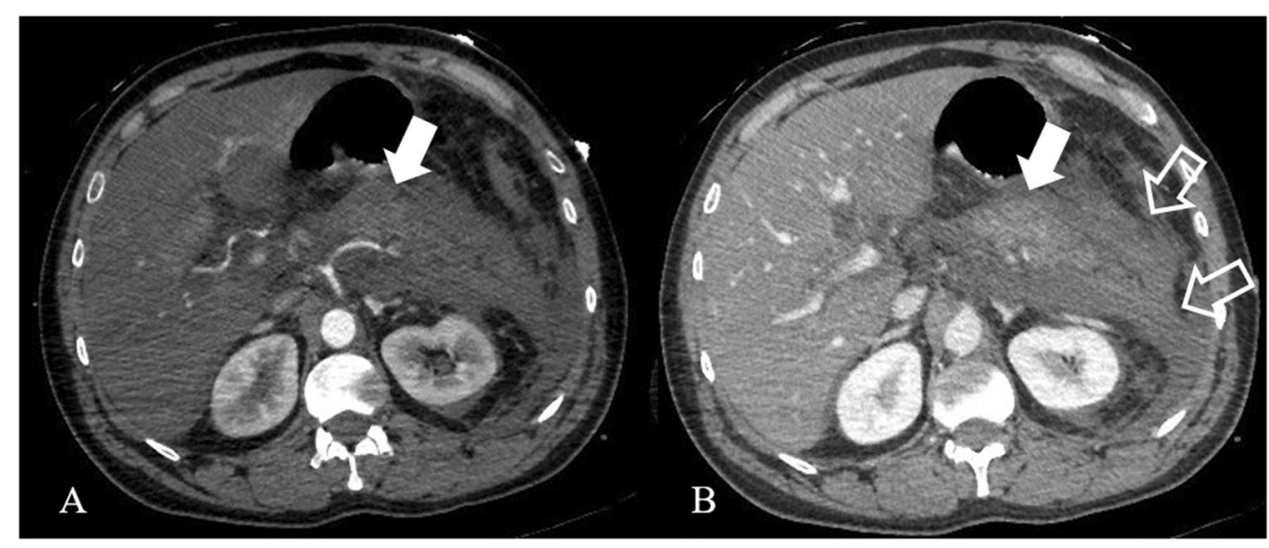

In the first few days of the illness, the pattern of perfusion of the pancreatic parenchyma as seen on CECT may be patchy, with variable attenuation before the area of impaired enhancement becomes more demarcated and/or confluent. In these cases, repeat CECT 5-6 days later is more accurate for the diagnosis of necrotizing pancreatitis [12] (Fig. 2b).

Imaging protocol varies by institution. CECT is usually performed employing a protocol depending on the clinical question; at our institution protocol includes an unenhanced scan, followed by arterial phase and portal venous phase. Unenhanced images may help to depict free intrabdominal fluid, for discriminating active bleeding from metal clips and calcification. The arterial phase on the upper abdomen is performed at 35-40 s after the initiation of IV contrast or 15-20 s after the peak enhancement, the so-called pancreatic phase with maximum contrast enhancement of the pancreatic parenchyma and then the portal venous phase from the top of the diaphragm, including the entire abdomen. Iodinated intravenous contrast is essential to evaluate of pancreatic necrosis, as well as evaluate for vascular complications such as pseudoaneurysm or splenic thrombosis (Fig. 4).

\section{Pancreatic and peripancreatic collections}

The revised Atlanta classification distinguishes different kinds of collections according to if they are purely fluid collections or containing necrotic debris in addiction to fluid and considering the time course ( $\leq 4$ weeks or $>4$ weeks from the onset of the pain).

In patients with IEP in the first 4 weeks acute peripancreatic fluid collections (APFCs) can occur, that are fluid collections in the peripancreatic region, with no well-defined walls and no internal solid components (Fig. 1). Most APFCs remain sterile and usually resolve spontaneously without intervention; on CECT they appear as homogeneous collections, with low attenuation, frequently seen in the 


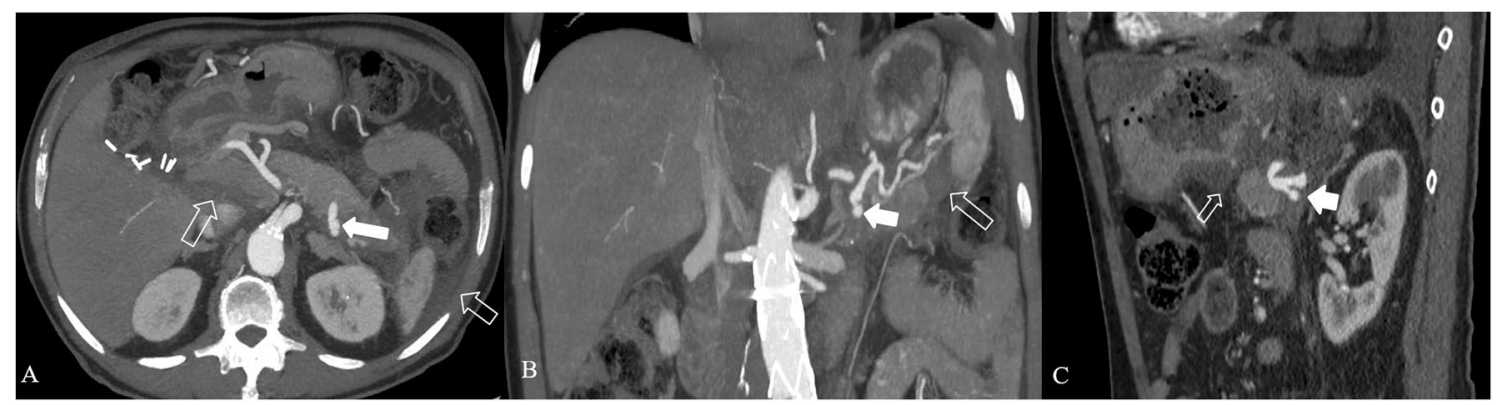

Fig. 4 Splenic artery pseudoaneurism in a 75 years-old man with RAP. The contrast-enhanced CT scans in the arterial phase axial MIP (a), coronal MIP MPR (b) and sagittal MPR (c) show splenic artery pseudoaneurism (white arrows), in a necrotizing pancreatitis

lesser sac and in the anterior pararenal space. If an APFCs has not resolved after 4 weeks, it becomes more organized and develops a capsule that manifests as an enhancing wall at CECT, containing only fluid, no necrosis. At this point the collection refers to as a pseudocyst, a well-circumscribed peripancreatic fluid collection, surrounded by a welldefined enhancing capsule (fibrous or granulation tissue) (Fig. 5). They generally resolve spontaneously, while the $50 \%$ of persistent pseudocysts will cause clinical symptoms or complications, which can include secondary infection, pain, hemorrhage secondary to erosion into adjacent vessels, decompression or rupture, or local mass effect (Table 2).

Acute necrotic collection (ACNs) present within the first 4 weeks of necrotising pancretitis and are poorly organized necrotic collections (Figs. 3, 6, 7, 8a-b). On CECT, ACNs are heterogeneous in appearance and have no definable wall enclosing the collection; however even if the collection is homogenous, it is considered ANC when associated with known pancreatic parenchymal necrosis. On unenhanced $\mathrm{CT}$, the presence of fat attenuation within a pancreatic collection is helpful at identifying necrosis and can also help differentiate between ANCs and APFCs [12, 15]. After with evident peri-pancreatic collection (empty arrows) extending up to anterior pararenal space of the retroperitoneum, gastrohepatic and gastrosplenic

4 weeks of necrotising pancreatitis ACNs become WON (walled off necrosis). It resembles a pseudocyst, but it can be differentiated on CECT by the presence of internal solid components (Figs. 9, 10). As ACNs, WON may be intra- or extra-pancreatic [12]. When WONs develop in the setting of a normally enhancing pancreas on CECT, a T2-weighted MRI or ultrasound may be necessary to help to identify the presence of debris in the fluid collection to distinguish WON from pseudocyst [22, 23] (Table 3).

\section{Complications}

Any collection can be sterile or infected, although infection occurs more frequently in necrotic collections. Infection should be clinically suspected since the only imaging finding of an infected collection is the presence of gas within the collection. Wall enhancement is not a reliable indicator of infection since it is invariably present in mature collections (pseudocysts and WONs). The gas often appears as multiple small bubbles scattered throughout the collection owing to the complex nature of necrotic collections [12].
Table 2 Pancreatic and peripancreatic collections in $\mathrm{IEP}^{12}$

\begin{tabular}{|c|c|c|c|c|}
\hline Collection & $\begin{array}{l}\text { Time after onset } \\
\text { of pain (week) }\end{array}$ & Location & $\begin{array}{l}\text { Imaging features } \\
\text { CECT }\end{array}$ & $\begin{array}{l}\text { Imaging features } \\
\text { MRI }\end{array}$ \\
\hline APFC & $\leq 4$ & Extra -pancreatic & $\begin{array}{l}\text { Homogeneous collection } \\
\text { with fluid density } \\
\text { Confined by normal peripan- } \\
\text { creatic fascial planes } \\
\text { No definable wall } \\
\text { Adjacent to pancreas (no } \\
\text { intrapancreatic extension) }\end{array}$ & $\begin{array}{l}\text { Homogeneously } \\
\text { hypointense on } \\
\text { T1WIs and hyperin- } \\
\text { tense on T2WI } \\
\text { No cystic walls and no } \\
\text { solid components }\end{array}$ \\
\hline Pseudo-cyst & $\geq 4$ & Extra-pancreatic & $\begin{array}{l}\text { Well defined wall } \\
\text { Usually round or oval } \\
\text { Homogeneous fluid density } \\
\text { No non-liquid component }\end{array}$ & $\begin{array}{l}\text { Thin smooth wall } \\
\text { Homogeneous inten- } \\
\text { sity on T1WIs and } \\
\text { T2WIs of the liquid } \\
\text { content } \\
\text { No solid component } \\
\text { or debris in the fluid }\end{array}$ \\
\hline
\end{tabular}




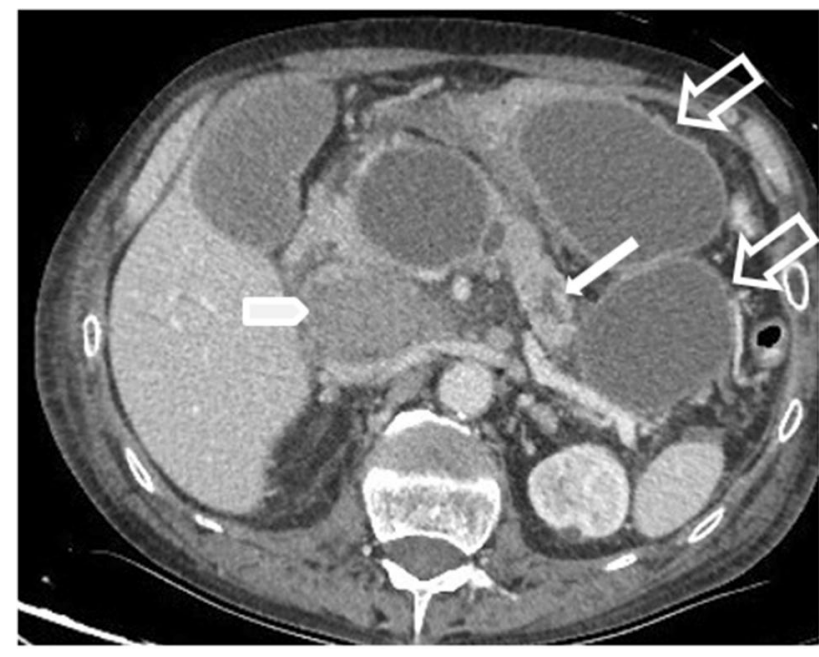

Fig. 5 Pseudocyst: 61 years old man, with history of alcohol abuse and hospitalized for necrotizing pancreatitis. Contrast-enhanced CT scan after 4 weeks from the onset, show a hyperdense collection in the retroperitoneum, behind the head of the pancreas and the duodenum (arrow head) suggesting previous bleeding. No signs of active bleeding were evident. Other pseudocysts are localized in the peripancreatic fat, between body and tail (empty arrows). Wirsung duct is also dilated (thin arrow)

Infected collections can also manifest with gas bubbles due to a pancreatic-enteric fistula, which can occasionally be seen when necrotic collections erode through the bowel wall, most commonly in the colon and the duodenum [24].

Patients with necrotizing pancreatitis require an individualized multidisciplinary management approach to reduce mortality and prevent associated complications. The nowadays accepted management is the "step-up" approach that aims to utilize the least invasive technique first, with progressive escalation for treatment failure [25]. Current evidence-based treatment includes an initial step of drainage (either percutaneous catheter or transluminal endoscopicFig. $8 \mathrm{c}-\mathrm{d}$ ) and then frequent re-evaluation of the clinical success of this approach. Surgical or endoscopic transluminal debridement is now only required with lack of clinical resolution and is delayed until necrosis has become WON [26].

Apart from collections, other complications may occur, such as vascular complications. Splenic vein thrombosis represents the most common vascular complication in patients with AP. The release of pancreatic enzymes in AP results in erosion of local vasculature which may lead pseudoaneurysm malformation as well as spontaneous hemorrhage; the most common source of bleeding is the splenic artery, portal vein, and other peripancreatic vessels [27]. Necrosis of the central pancreas results in the disruption of the main pancreatic duct in $40 \%$ of cases, that can be confirmed with pancreatic MRI and MRCP (Magnetic Resonance
Cholangiopancreatography) (Fig. 11). Other complications of necrotizing pancreatitis are pancreatic duct strictures (Fig. 2), which may develop secondary to inflammation or healing following successful drainage of necrotic collections [27].

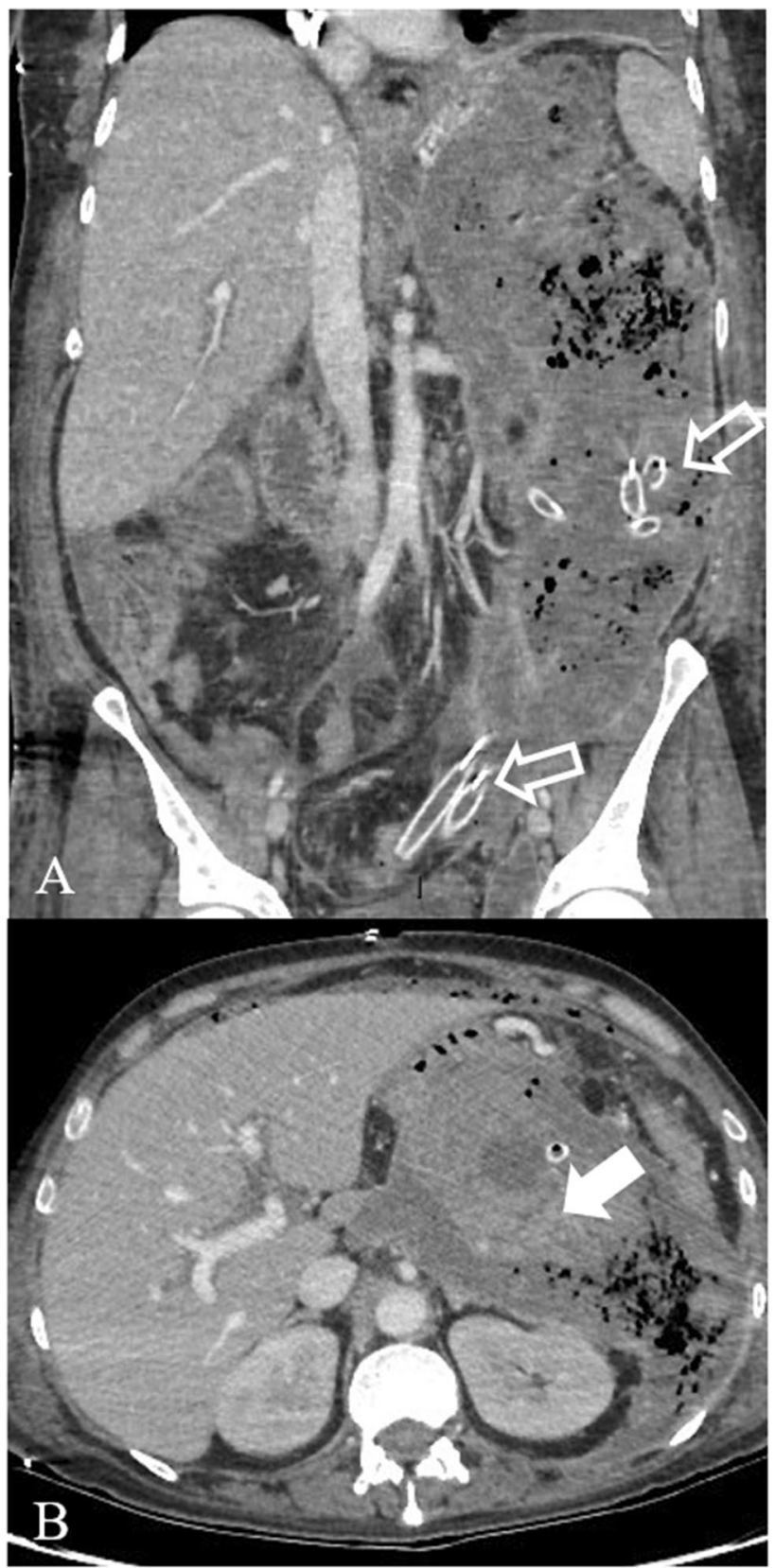

Fig. 6 Necrotizing Pancreatitis. The same case as the previous in Fig. 3, after 1 month of the onset of the symptoms, and 1 week after surgical necrosectomy, the contrast-enhanced CT scans in the portal phase show a peri-pancreatic collection with bubbles air and drainage tubes in the collection (empty arrows). Coronal MPR image (a) shows the extention of the collection. Axial scan (b) show diffuse alterations of the $\mathrm{CE}$ of the parenchyma, due to necrosis (arrow) 


\section{Role of MRI in AP}

In the emergency setting $\mathrm{CT}$ and ultrasound are the imaging modalities of choice because of accessibility, speed, and lower cost. Indeed, in the early phase of AP a CECT study, at 5-7 days after admission, is generally performed. In the late phase of moderately severe or severe acute pancreatitis, local complications evolve completely, such as the presence of infection within areas of necrosis. Since different local complications may require a variety of interventions, it is important to distinguish between them. For these reasons MRI has its own rule, more in the late phase, having a superior soft tissue contrast resolution and allowing better assessment of biliary and pancreatic ducts. MRI also does not use ionizing radiation, but it requires patient co-operation.

Normal pancreatic anatomy is best depicted on T1 weighted fat-suppressed images, in which the pancreas is typically hyperintense because of pancreatic acinar proteins $[28,29]$; on $\mathrm{T} 2$ weighted images, pancreatic parenchyma is typically hypointense. In necrotizing pancreatitis, the necrotic area displays hypointensity on T1WI, hyperintensity on T2WI and no enhancement after an injection of contrast agent such as Gd-DTPA [30]; if the necrotic zones on
MRI contain gas may indicate infection [22]. On MRI scans acute peripancreatic fluid collections (APFCs) are homogeneously hypointense on T1WIs and hyperintense on T2WI, with no cystic walls and no solid components. On MRI pancreatic pseudocysts have a thin smooth wall, homogeneous intensity on T1WIs and T2WIs of the liquid content, and no solid component or debris in the fluid (Fig. 12). Pancreatic juice constantly overflows from the ruptured pancreatic duct, leading to a gradual enlargement of the cysts; for surgical indications it is important to visualize where the pancreatic duct breaks and its extent of rupture [31], for this reason T2WI, and also MRCP and multiplanar reconstruction are generally performed. MR with MRCP may be helpful in treatment planning of pancreatic pseudocysts by assessing the internal content and by displaying the relationship with the stomach or the duodenum to plan pseudocystostomy.

ANCs have no capsules, and they show mixed signals on T1WI and T2WI (Fig. 13); although MRI is sensitive in differentiating different components in the accumulation of peripancreatic tissue, when the necrotic tissue fragments are small, MRI cannot determine whether the liquid that appears with high signal on the liquid-suppressed T2WI is entirely inflammatory fluid without doping necrotic cells, and thus,

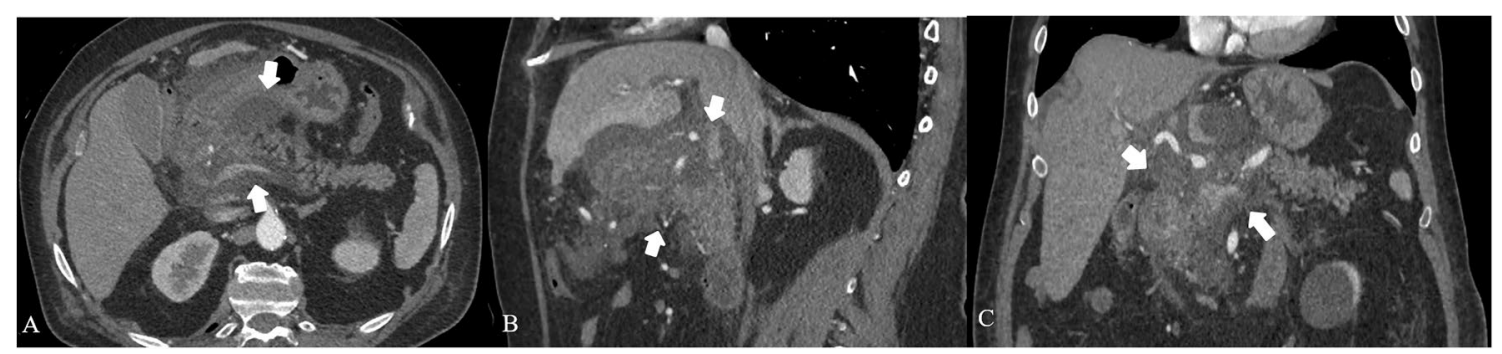

Fig. 7 ANCs in biliary AP in a 74 years-old man. The contrastenhanced CT axial scan (a) shows the presence of an acute necrotic fluid collection (ANCs) interesting the head and the body of the pan- creatic gland (white arrows), extending in the fat surrounding the gland up to the gastrohepatic ligament. The sagittal MPR (b) and coronal (c) better show the extention of the collection

Table 3 Pancreatic and peripancreatic collections in necrotizing pancreatitis ${ }^{12}$

\begin{tabular}{|c|c|c|c|c|}
\hline Collection & $\begin{array}{l}\text { Time after } \\
\text { onset of pain } \\
\text { (week) }\end{array}$ & Location & $\begin{array}{l}\text { Imaging features } \\
\text { CECT }\end{array}$ & $\begin{array}{l}\text { Imaging features } \\
\text { MRI }\end{array}$ \\
\hline ANC & $\leq 4$ & Intra- and/or extra-pancreatic & $\begin{array}{l}\text { Heterogeneous and non- } \\
\text { liquid density of varying } \\
\text { degrees in different } \\
\text { locations } \\
\text { No definable wall encap- } \\
\text { sulating the collection }\end{array}$ & $\begin{array}{l}\text { Mixed signals on T1WI and T2WI } \\
\text { Necrotic tissue fragments in the collection }\end{array}$ \\
\hline WON & $\geq 4$ & Intra- and/or extra-pancreatic & $\begin{array}{l}\text { Encapsulated collection of } \\
\text { pancreatic and/or peri- } \\
\text { pancreatic necrosis } \\
\text { Heterogeneous } \\
\text { Well defined wall }\end{array}$ & $\begin{array}{l}\text { Encapsulated effusion contains non-liquid substances, } \\
\text { flocculent, with banded tissue fragments, free and } \\
\text { floating }\end{array}$ \\
\hline
\end{tabular}


MRI still cannot accurately determine ANCs [32]. The maturation stage of ANCs is the WON that on MRI scans appear as encapsulated effusion contains non-liquid substances, flocculent, with banded tissue fragments, free and floating, and there is no enhanced signal on the enhanced scans (Figs. 9b; 10); patients with WON are commonly complicated with infection.

The severe necrotic pancreatitis with pancreatic duct disruption, called disconnected pancreatic duct syndrome (DPDS) (Fig. 14), has $10 \%$ to $31 \%$ as prevalence [33]. In these cases, the combination of MRI and MRCP provides a noninvasive method showing not only the pancreas and peripancreatic changes but also analyzing the proximal and distal ends of the ruptured main pancreatic duct and possible fistula. Therefore, the use of MRI and MRCP is more advantageous to evaluate the main disconnected pancreatic duct syndrome caused by acute necrotizing pancreatitis [34]. As the severity increases, the incidence of pancreatic duct rupture also increases. The diagnosis of pancreatic duct disruption should be considered if there is a peripancreatic necrosis area at least $2 \mathrm{~cm}$, and MRCP shows that the main pancreatic duct of the upstream pancreatic tissue travels to the WON area of the intra and/or extra pancreatic tissue.
MRCP performed with secretin is emerging as the imaging study of choice for the diagnosis of a disconnected pancreatic duct, which demonstrates a cutoff of the downstream pancreatic duct with enhancing upstream pancreatic parenchyma [35]; S-MRCP may on occasion shows the passage of exocrine output into the collection.

MRI is also sensitive to visualizing hemorrhages, which are hyperintense on T1WI during acute phase and have signals that persist longer than on CT images [36].

MRI can have a role in the identification of the etiology (alcohol and choledocholithiasis), especially MRCP in biliary microlithiasis, it is superior to $\mathrm{CT}$ in showing small ductal calculi, evaluating the pancreatic duct and biliary tree, demonstrating high sensitivity and specificity, and adding benefit of potentially obviating the more invasive ERCP [37-40].

\section{Recurrent acute pancreatitis (RAP)}

After therapy, most patients with AP recover completely, but some of them can have other new episode and are said to have recurrent acute pancreatitis. RAP has been defined as a
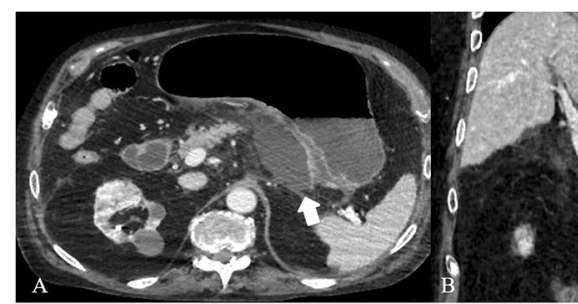

Fig. 8 Necrotizing AP in a 74 years-old man with a history of AP, 3 weeks after the onset. The contrast-enhanced CT axial scan (a) and the coronal MPR (b) show the presence of collection in the lesser sac up to the lesser curvature of the stomach (white arrows). The contrast-enhanced CT axial scan (c) and the coronal MPR (d) 5 days after the previous examination show the drainage of the collection by cystogastrostomy (empy arrow), and the presence of gas-collection (thin arrow in $\mathbf{c}$ )

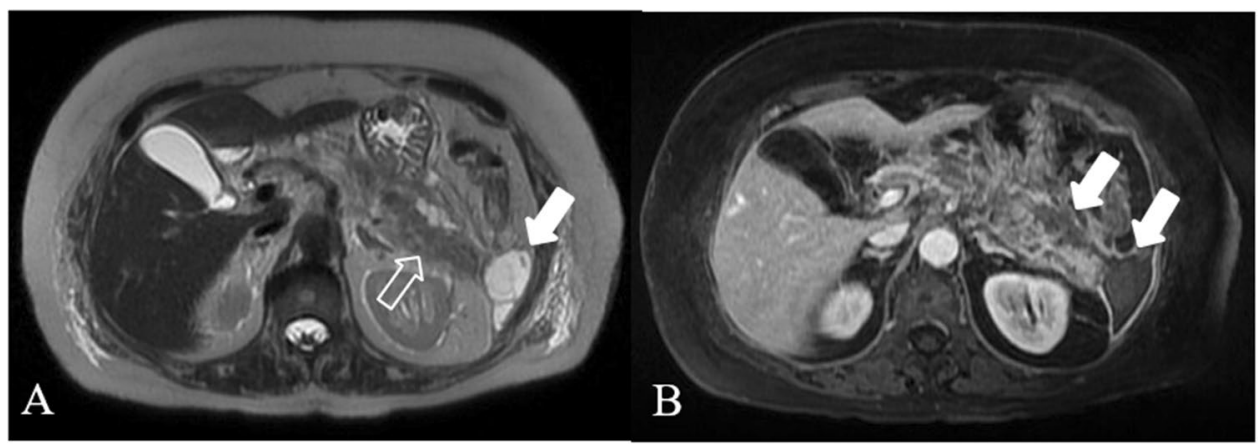

Fig. 9 Walled off necrosis. 73 years old woman undergoing statins and amiodarone treatment. T2 weighted MR image (a) and postgadolinium $\mathrm{T} 1 \mathrm{w}$ scan (b), show the presence of a heterogeneous encapsulated fluid collection suggesting walled-off necrosis (WON); the WON extends in the pancreatic and peripancreatic area, up to the left anterior pararenal space and left paracolic space (arrows). Diffuse hyperintensity on $\mathrm{T} 2 \mathrm{w}$ images of the pancreatic parenchyma indicates the presence of parenchymal edema (empty arrow in $\mathbf{a})$ 


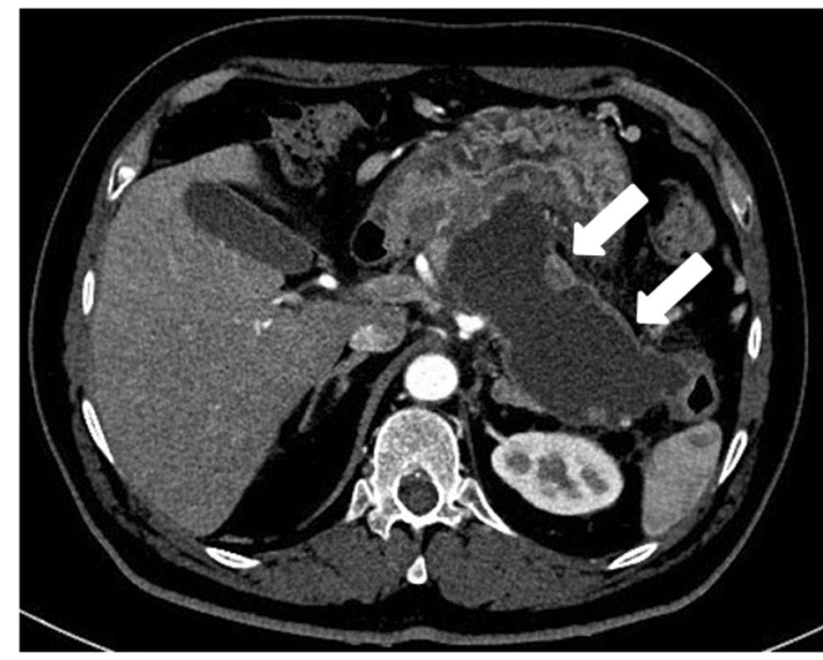

Fig. 10 WON evolution. Acute necrotizing pancreatitis in a 61-yearsold man. Four weeks after the onset axial CECT scan shows the presence of an encapsulated collection (WON) in the peripancreatic fat near the body and the tail of the gland (arrows) syndrome of multiple distinct acute inflammatory responses originating within the pancreas in individuals with genetic, environmental, traumatic, morphologic, metabolic, biologic, and/or other risk factors who experienced 2 or more episodes of documented AP, separated by at least 3 months.

Idiopathic recurrent acute pancreatitis is defined as RAP after exclusion of readily apparent causes by history, routine laboratory tests, and conventional imaging, not necessarily including MRCP, EUS (transesophageal endoscopic ultrasound), ERCP with or without manometry, or genetic testing (grade 1B, $75 \%$ probably or definitely agree with the definition) [41]. For 70-80\% of patients with RAP, a specific cause may be identified [42] such as gallstone disease (especially biliary microlithiasis), excessive alcohol consumption, hypertriglyceridemia, medications, intraductal papillary mucinous neoplasms (IPMNs), genetic mutations, hypercalcemia, sphincter of Oddi dysfunction, and pancreatobiliary ductal anomalies. Apart from laboratory and imaging tests to identify causes of acute pancreatitis,

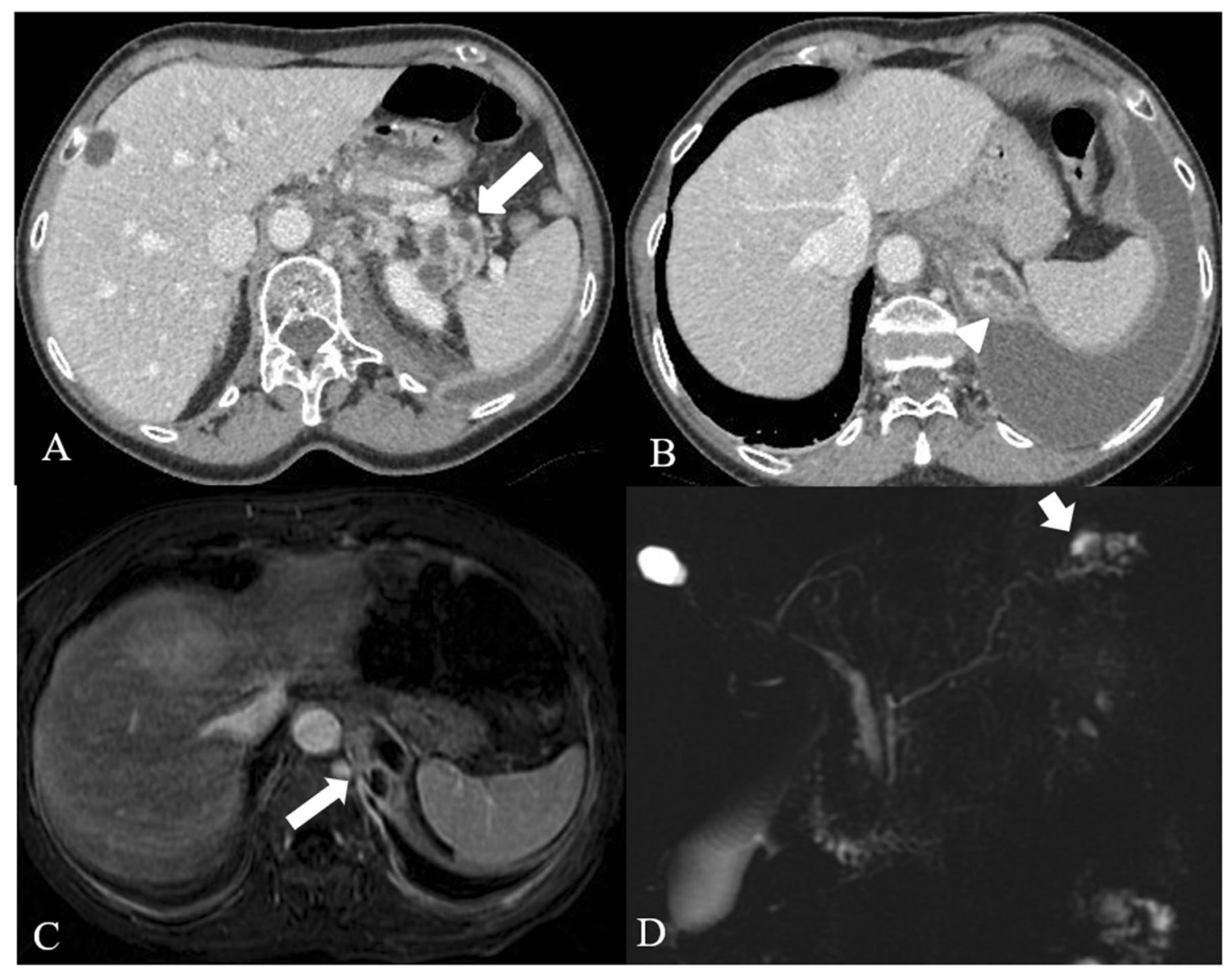

Fig. 11 Fistula with pleural cavity in a 66 years-old woman with acute necrotizing pancreatitis. Multiple encapsulated fluid collections in the tail of the pancreatic parenchyma (arrow in a), as for necrotic spots. These collections extend upt to the left hemidiaphragm with pleural fistula and pleural effusion (arrowhead in b). Axial (c) post contrast T1w MR images and MRCP (d) confirm the pleural fistula (arrows) 


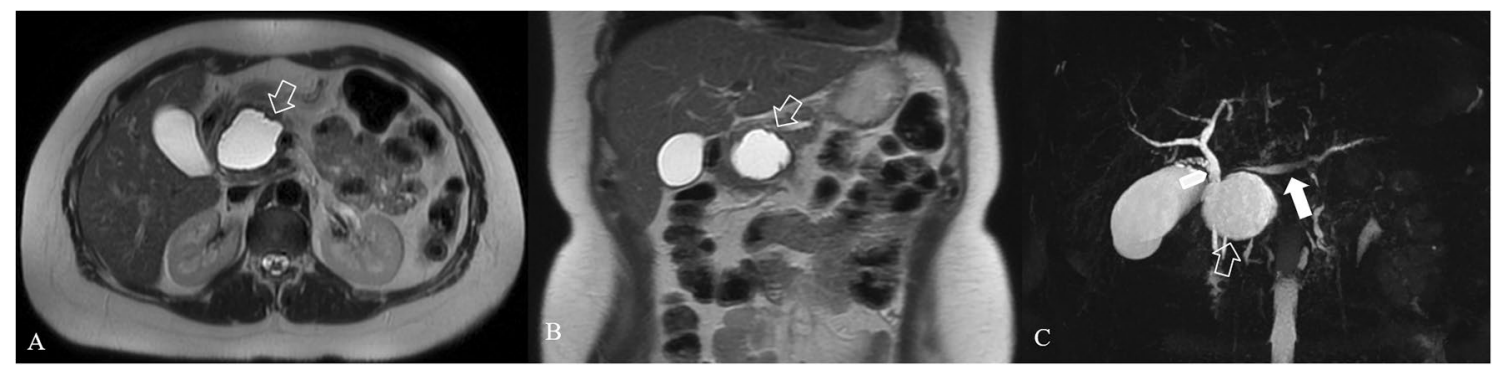

Fig. 12 Pseudocyst in a 36 years-old woman, with AP, 12 weeks from the onset. Axial scan (a) and coronal scan (b) show the hyperintense collection in $\mathrm{T} 2$ weighted image (empty arrow) with dilated pancre- atic duct (white arrow). MRCP (c) shows bile duct dilatation (arrowhead), due to the compression from the collection

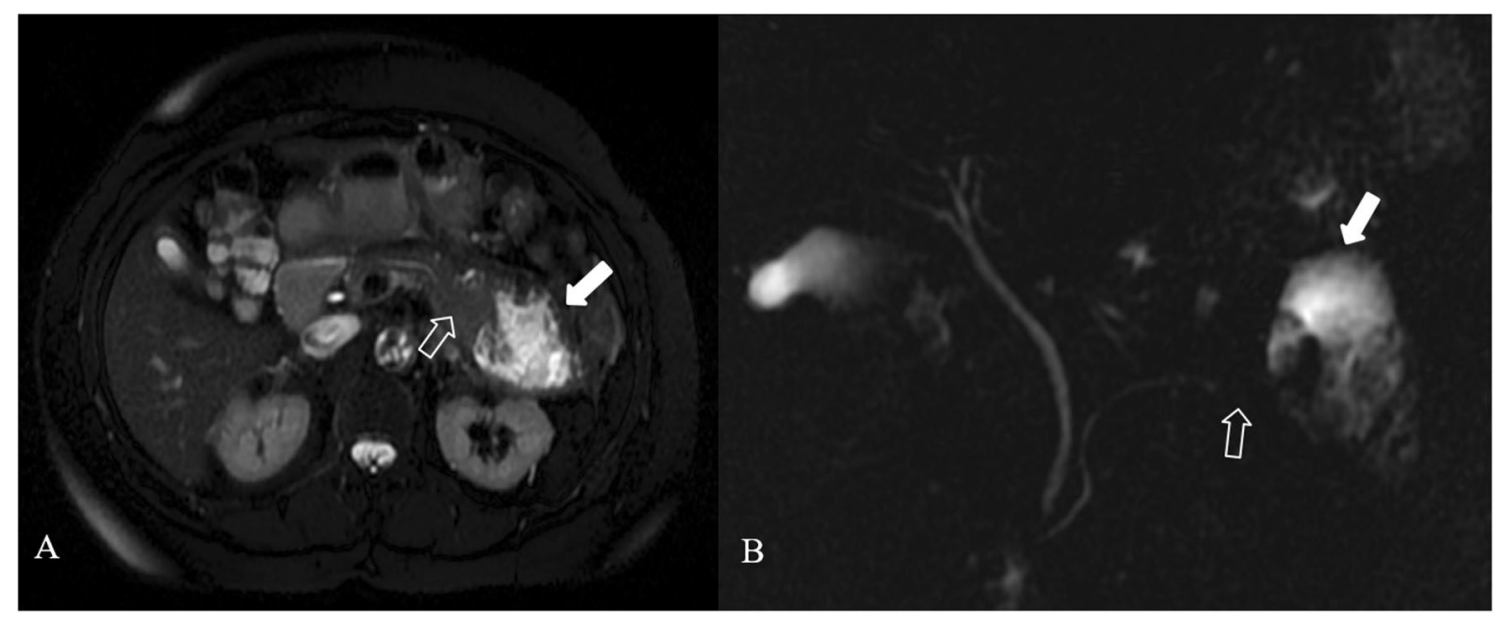

Fig. 13 ACNs in a 72 years-old woman. T2 weighted MR image (a) and MRCP (b) 2 weeks after the onset show a heterogeneous collection in the pancreatic tail (white arrow), where there is a focal interruption of the Wirsung duct (empty arrow)

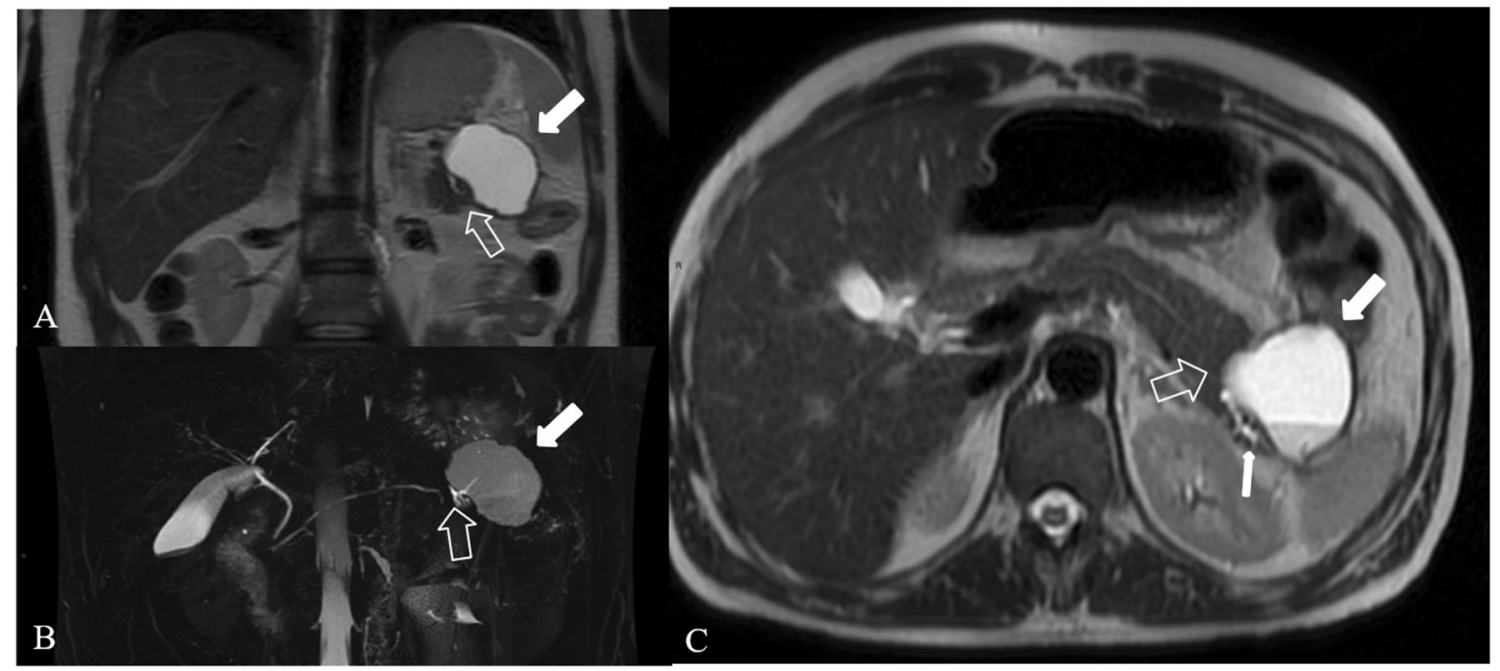

Fig. 14 Disconnected pancreatic duct syndrome in a 41 years-old man. Coronal (a), axial (c) T2 weighted MR images and MRCP (b) 3 weeks after the onset of the symptoms show focal interruption of the Wirsung duct (empty arrow)—upstream pancreatic duct dilatation (thin arrow in c) - and a heterogeneous encapsulated fluid collection in the pancreatic tail (white arrow) 
the investigation of RAP requires a detailed assessment of pancreatic ductal anatomy. MRCP enables the evaluation of ductal anatomy, to identify parenchymal abnormalities including cystic lesions and may be the best available test to diagnose non-calcific chronic pancreatitis; it should be considered a key component in the evaluation of RAP [43]. MRCP can be performed also after the intravenous injection of secretin, that stimulates water and bicarbonate secretions from the exocrine cells of the pancreas leading to more conspicuous visualization of main pancreatic duct and diseased side branches. Secretin-enhanced MRCP is useful in showing potentially treatable causes of RAP, such as divisum anatomy, ductal strictures and gives an assessment of the exocrine function of the gland [44]. A study comparing patients with RAP to community control subjects showed a higher frequency of divisum in patients with RAP [45]. It is clinical practice to investigate for anomalous ductal anatomy in patients with recurrent acute pancreatitis, indeed secretinenhanced MRCP (S-MRCP) can reveal morphologic features of ductal anatomy like a cystic dilatation of the end of the Santorinicele, multiple dilated side branches, or subclinical ductal changes of chronic pancreatitis, obviating the need for ERCP. It has been seen also that functional deficiencies occur in about one-third of patients with RAP, even when no anatomic ductal disease is found, adding to S-MRCP the potential to quantify pancreatic exocrine reserve. S-MRCP has a higher sensitivity and specificity (86\%) compared with routine MRCP (57\%) for diagnosing divisum, and it is superior also in diagnosing main duct dilation, $86 \%$ versus $42 \%$ [45]. The most impressive added benefit of se-cretinenhanced MRCP is the detection of side branch dilation, suggesting the superior of S-MRCP to conventional MRCP for the diagnosis of early chronic pancreatitis. By the way it is important to underline that secretin is an expensive drug.

\section{Conclusion}

AP is an evolving condition, whose severity may change during the disease. In the early phase, during the first week after onset, the disease manifests as a systemic inflammatory response; at this time clinical severity and treatment are mainly determined based on type and degree of organ failure. In the late phase, from the second week to months, imaging plays an important role in the diagnosis and staging. Wider availability and good image quality make CT the mostly used imaging technique. In a good report the radiologists must define the type of AP and its complications; it should include a statement about the presence or absence of necrosis about the location and the amount of necrotic gland. Also, local complication should be described in the terms of location, size, appearance, and presence or absence of a mature wall. The collection should be named according to the revised Atlanta classification lexicon, and the impression section should contain a summary of the findings in order to standardize treatment, communicate imaging appearance using common terminology, and hopefully improve patient outcomes.

Acknowledgements This work was not sponsored by grants or any funding organization or company.

Authors' contribution All authors designed, wrote, and reviewed this article. All authors read and approved the final manuscript.

Funding Open access funding provided by Università Cattolica del Sacro Cuore within the CRUI-CARE Agreement. This work was not sponsored by grants or any funding organization or company.

Availability of data and materials Data sharing is not applicable to this article as no datasets were generated or analyzed.

\section{Declarations}

Conflict of interests The authors declare that they have no competing interests.

Consent to participate All patients have signed consent forms agreeing that their images and data could be used for educational and research purposes.

Ethical approval All patients have signed consent forms agreeing that their images and data ceeing that their images and data could be used for educational and research purposes.

Open Access This article is licensed under a Creative Commons Attribution 4.0 International License, which permits use, sharing, adaptation, distribution and reproduction in any medium or format, as long as you give appropriate credit to the original author(s) and the source, provide a link to the Creative Commons licence, and indicate if changes were made. The images or other third party material in this article are included in the article's Creative Commons licence, unless indicated otherwise in a credit line to the material. If material is not included in the article's Creative Commons licence and your intended use is not permitted by statutory regulation or exceeds the permitted use, you will need to obtain permission directly from the copyright holder. To view a copy of this licence, visit http://creativecommons.org/licenses/by/4.0/.

\section{References}

1. Petrov MS, Yadav D (2019) Global epidemiology and holistic prevention of pancreatitis. Nat Rev Gastroenterol Hepatol 16(3):175184. https://doi.org/10.1038/s41575-018-0087-5

2. Petrov MS (2013) Editorial: abdominal fat: a key player in metabolic acute pancreatitis. Am J Gastroenterol 108(1):140-142. https://doi.org/10.1038/ajg.2012.384

3. Yadav D, Papachristou GI, Whitcomb DC (2007) Alcohol-associated pancreatitis. Gastroenterol Clin North Am 36(2):219-vii. https://doi.org/10.1016/j.gtc.2007.03.005

4. Xiao AY, Tan ML, Wu LM, Asrani VM, Windsor JA, Yadav D, Petrov MS (2016) Global incidence and mortality of pancreatic diseases: a systematic review, meta-analysis, and meta-regression 
of population-based cohort studies. Lancet Gastroenterol Hepatol 1(1):45-55. https://doi.org/10.1016/S2468-1253(16)30004-8

5. Pendharkar SA, Mathew J, Petrov MS (2017) Age- and sex-specific prevalence of diabetes associated with diseases of the exocrine pancreas: a population-based study. Dig Liver Dis Off J Ital Soc Gastroenterol Ital Assoc Study Liver 49(5):540-544. https:// doi.org/10.1016/j.dld.2016.12.010

6. Lee YK, Huang MY, Hsu CY, Su YC (2016) Bidirectional relationship between diabetes and acute pancreatitis: a populationbased cohort study in taiwan. Medicine 95(2):e2448. https://doi. org/10.1097/MD.0000000000002448

7. Shen HN, Yang CC, Chang YH, Lu CL, Li CY (2015) Risk of diabetes mellitus after first-attack acute pancreatitis: a national population-based study. Am J Gastroenterol 110(12):1698-1706. https://doi.org/10.1038/ajg.2015.356

8. Frey C, Zhou H, Harvey D, White RH (2007) Co-morbidity is a strong predictor of early death and multi-organ system failure among patients with acute pancreatitis. J Gastrointest Surg Off J Soc Surg Aliment Tract 11(6):733-742. https://doi.org/10.1007/ s11605-007-0164-5

9. Hong S, Qiwen B, Ying J, Wei A, Chaoyang T (2011) Body mass index and the risk and prognosis of acute pancreatitis: a metaanalysis. Eur J Gastroenterol Hepatol 23(12):1136-1143. https:// doi.org/10.1097/MEG.0b013e32834b0e0e

10. Petrov MS, Shanbhag S, Chakraborty M, Phillips AR, Windsor JA (2010) Organ failure and infection of pancreatic necrosis as determinants of mortality in patients with acute pancreatitis. Gastroenterology 139(3):813-820. https://doi.org/10.1053/j.gastro. 2010.06.010

11. Crockett SD, Wani S, Gardner TB, Falck-Ytter Y, Barkun AN, Committee AGAICG (2018) American gastroenterological association institute guideline on initial management of acute pancreatitis. Gastroenterology 154(4):1096-1101. https://doi.org/10. 1053/j.gastro.2018.01.032

12. Banks PA, Bollen TL, Dervenis C, Gooszen HG, Johnson CD, Sarr MG, Tsiotos GG, Vege SS, Acute Pancreatitis Classification Working Group (2013) Classification of acute pancreatitis-2012: revision of the Atlanta classification and definitions by international consensus. Gut 62(1):102-111. https://doi.org/10.1136/ gutjnl-2012-302779

13. Bollen TL, van Santvoort HC, Besselink MG, van Es WH, Gooszen HG, van Leeuwen MS (2007) Update on acute pancreatitis: ultrasound, computed tomography, and magnetic resonance imaging features. Semin Ultrasound CT MR 28(5):371-383. https:// doi.org/10.1053/j.sult.2007.06.002

14. Morgan DE (2008) Imaging of acute pancreatitis and its complications. Clin Gastroenterol Hepatol Off Clin Pract J Am Gastroenterol Assoc 6(10):1077-1085. https://doi.org/10.1016/j.cgh.2008. 07.012

15. Foster BR, Jensen KK, Bakis G, Shaaban AM, Coakley FV (2016) Revised atlanta classification for acute pancreatitis: a pictorial essay. Radiogr Rev Publ Radiol Soc North Am, Inc 36(3):675-687

16. Johnson CD, Abu-Hilal M (2004) Persistent organ failure during the first week as a marker of fatal outcome in acute pancreatitis. Gut 53(9):1340-1344. https://doi.org/10.1136/gut.2004.039883

17. Mofidi R, Duff MD, Wigmore SJ, Madhavan KK, Garden OJ, Parks RW (2006) Association between early systemic inflammatory response, severity of multiorgan dysfunction and death in acute pancreatitis. Br J Surg 93(6):738-744. https://doi.org/10. 1002/bjs.5290

18. Lytras D, Manes K, Triantopoulou C, Paraskeva C, Delis S, Avgerinos C, Dervenis C (2008) Persistent early organ failure: defining the high-risk group of patients with severe acute pancreatitis? Pancreas 36(3):249-254. https://doi.org/10.1097/MPA. 0b013e31815acb2c
19. Singh VK, Bollen TL, Wu BU, Repas K, Maurer R, Yu S, Mortele KJ, Conwell DL, Banks PA (2011) An assessment of the severity of interstitial pancreatitis. Clin Gastroenterol Hepatol Off Clin Pract J Am Gastroenterol Assoc 9(12):1098-1103. https://doi.org/ 10.1016/j.cgh.2011.08.026

20. Mortele KJ, Wiesner W, Intriere L, Shankar S, Zou KH, Kalantari BN, Perez A, vanSonnenberg E, Ros PR, Banks PA, Silverman SG (2004) A modified CT severity index for evaluating acute pancreatitis: improved correlation with patient outcome. AJR Am J Roentgenol 183(5):1261-1265. https://doi.org/10.2214/ajr.183.5. 1831261

21. Spanier BW, Nio Y, van der Hulst RW, Tuynman HA, Dijkgraaf MG, Bruno MJ (2010) Practice and yield of early CT scan in acute pancreatitis: a dutch observational multicenter study. Pancreatol Off J Int Assoc Pancreatol (IAP) ... [et al.] 10(2-3):222-228. https://doi.org/10.1159/000243731

22. Türkvatan A, Erden A, Türkoğlu MA, Seçil M, Yüce G (2015) Imaging of acute pancreatitis and its complications. Part 2: complications of acute pancreatitis. Diagn Interv Imaging 96(2):161169. https://doi.org/10.1016/j.diii.2013.12.018

23. Zhao K, Adam SZ, Keswani RN, Horowitz JM, Miller FH (2015) Acute pancreatitis: revised atlanta classification and the role of cross-sectional imaging. AJR A J Roentgenol 205(1):W32-W41. https://doi.org/10.2214/AJR.14.14056

24. Tüney D, Altun E, Barlas A, Yegen C (2008) Pancreatico-colonic fistula after acute necrotizing pancreatitis. Diagnosis with spiral CT using rectal water soluble contrast media. JOP J Pancreas 9(1):26-29

25. van Santvoort HC, Besselink MG, Bakker OJ, Hofker HS, Boermeester MA, Dejong $\mathrm{CH}$, van Goor $\mathrm{H}$, Schaapherder AF, van Eijck CH, Bollen TL, van Ramshorst B, Nieuwenhuijs VB, Timmer R, Laméris JS, Kruyt PM, Manusama ER, van der Harst E, van der Schelling GP, Karsten T, Hesselink EJ, van Laarhoven CJ, Rosman C, Bosscha K, de Wit RJ, Houdijk AP, van Leeuwen MS, Buskens E, Gooszen HG, Dutch Pancreatitis Study Group (2010) A step-up approach or open necrosectomy for necrotizing pancreatitis. N Engl J Med 362(16):1491-502. https://doi.org/10. 1056/NEJMoa0908821

26. da Costa DW, Boerma D, van Santvoort HC, Horvath KD, Werner J, Carter CR, Bollen TL, Gooszen HG, Besselink MG, Bakker OJ (2014) Staged multidisciplinary step-up management for necrotizing pancreatitis. Br J Surg 101(1):e65-e79. https://doi. org/10.1002/bjs.9346

27. Shyu JY, Sainani NI, Sahni VA, Chick JF, Chauhan NR, Conwell DL, Clancy TE, Banks PA, Silverman SG (2014) Necrotizing pancreatitis: diagnosis, imaging, and intervention. Radiogr Rev Publ Radiol Soc North Am Inc 34(5):1218-1239. https://doi.org/10. 1148/rg.345130012

28. Ditkofsky NG, Singh A, Avery L, Novelline RA (2014) The role of emergency MRI in the setting of acute abdominal pain. Emerg Radiol 21(6):615-624. https://doi.org/10.1007/ s10140-014-1232-2

29. Miller FH, Keppke AL, Dalal K, Ly JN, Kamler VA, Sica GT (2004) MRI of pancreatitis and its complications: part 1, acute pancreatitis. AJR Am J Roentgenol 183(6):1637-1644. https:// doi.org/10.2214/ajr.183.6.01831637

30. Sun H, Zuo HD, Lin Q, Yang DD, Zhou T, Tang MY, Wáng Y, Zhang XM (2019) MR imaging for acute pancreatitis: the current status of clinical applications. Ann Transl Med 7(12):269. https:// doi.org/10.21037/atm.2019.05.37

31. Sandrasegaran K, Tann M, Jennings SG, Maglinte DD, Peter SD, Sherman S, Howard TJ (2007) Disconnection of the pancreatic duct: an important but overlooked complication of severe acute pancreatitis. Radiogr Rev Publ Radiol Soc North Am Inc 27(5):1389-1400. https://doi.org/10.1148/rg.275065163 
32. Dhaka N, Samanta J, Kochhar S, Kalra N, Appasani S, Manrai M, Kochhar R (2015) Pancreatic fluid collections: what is the ideal imaging technique? World J Gastroenterol 21(48):13403-13410. https://doi.org/10.3748/wjg.v21.i48.13403

33. Uomo G, Molino D, Visconti M, Ragozzino A, Manes G, Rabitti PG (1998) The incidence of main pancreatic duct disruption in severe biliary pancreatitis. Am J Surg 176(1):49-52. https://doi. org/10.1016/s0002-9610(98)00097-X

34. Xiao B, Zhang XM, Tang W, Zeng NL, Zhai ZH (2010) Magnetic resonance imaging for local complications of acute pancreatitis: a pictorial review. World J Gastroenterol 16(22):2735-2742. https:// doi.org/10.3748/wjg.v16.i22.2735

35. Tirkes T, Sandrasegaran K, Sanyal R, Sherman S, Schmidt CM, Cote GA, Akisik F (2013) Secretin enhanced MR cholangiopancreatography: spectrum of findings. J Radiogr Rev Publ Radiol Soc North Am Inc 33(7):1889-1906

36. Tang MY, Chen TW, Bollen TL, Wang YX, Xue HD, Jin ZY, Huang XH, Xiao B, Li XH, Ji YF, Zhang XM (2018) MR imaging of hemorrhage associated with acute pancreatitis. Pancreatol Off J Int Assoc Pancreatol (IAP) ... [et al.] 18(4):363-369. https://doi. org/10.1016/j.pan.2018.03.004

37. Moon JH, Cho YD, Cha SW, Cheon YK, Ahn HC, Kim YS, Kim YS, Lee JS, Lee MS, Lee HK, Shim CS, Kim BS (2005) The detection of bile duct stones in suspected biliary pancreatitis: comparison of MRCP, ERCP, and intraductal US. Am J Gastroenterol 100(5):1051-1057. https://doi.org/10.1111/j.1572-0241. 2005.41057.x

38. Bates DD, LeBedis CA, Soto JA, Gupta A (2016) Use of magnetic resonance in pancreaticobiliary emergencies. Magn Reson Imaging Clin North Am 24(2):433-448. https://doi.org/10.1016/j.mric. 2015.11.010

39. Hirohashi S, Hirohashi R, Uchida H, Akira M, Itoh T, Haku E, Ohishi H (1997) Pancreatitis: evaluation with MR cholangiopancreatography in children. Radiology 203(2):411415. https://doi.org/10.1148/radiology.203.2.9114096

40. Darge K, Anupindi S (2009) Pancreatitis and the role of US, MRCP and ERCP. Pediatr Radiol 39(Suppl 2):S153-S157. https:// doi.org/10.1007/s00247-009-1145-5

41. Guda NM, Muddana V, Whitcomb DC, Levy P, Garg P, Cote G, Uc A, Varadarajulu S, Vege SS, Chari ST, Forsmark CE, Yadav D, Reddy DN, Tenner S, Johnson CD, Akisik F, Saluja AK, Lerch MM, Mallery JS, Freeman ML (2018) Recurrent acute pancreatitis: international state-of-the-science conference with recommendations. Pancreas 47(6):653-666. https://doi.org/10.1097/MPA. 0000000000001053

42. Testoni PA (2014) Acute recurrent pancreatitis: etiopathogenesis, diagnosis and treatment. World J Gastroenterol 20(45):1689116901. https://doi.org/10.3748/wjg.v20.i45.16891

43. Testoni PA, Mariani A, Curioni S, Zanello A, Masci E (2008) MRCP-secretin test-guided management of idiopathic recurrent pancreatitis: long-term outcomes. Gastrointest Endosc 67(7):1028-1034. https://doi.org/10.1016/j.gie.2007.09.007

44. Sandrasegaran K, Tahir B, Barad U, Fogel E, Akisik F, Tirkes T, Sherman S (2017) The value of secretin-enhanced MRCP in patients with recurrent acute pancreatitis. AJR Am J Roentgenol 208(2):315-321. https://doi.org/10.2214/AJR.16.16566

45. Gonoi W, Akai H, Hagiwara K, Akahane M, Hayashi N, Maeda E, Yoshikawa T, Tada M, Uno K, Ohtsu H, Koike K, Ohtomo $\mathrm{K}$ (2011) Pancreas divisum as a predisposing factor for chronic and recurrent idiopathic pancreatitis: initial in vivo survey. Gut 60(8):1103-1108. https://doi.org/10.1136/gut.2010.230011

Publisher's Note Springer Nature remains neutral with regard to jurisdictional claims in published maps and institutional affiliations. 